\title{
El éxodo: estructura fundante de la migración Alcance de la constitución trascendental del viandante como fundación ética
}

\author{
GERMÁN VARGAS GUILLÉN* \\ Universidad Pedagógica Nacional (Colombia) \\ gevargas@pedagogica.edu.co
}

\begin{abstract}
Resumen
Tanto la migración como el exilio, al lado del extranjero y el extraño, han sido objeto de la investigación fenomenológica. En este estudio se da un pequeño paso con respecto a la fenomenología de la migración. En particular, se lleva a cabo una profundización en torno a un estrato fundante: el éxodo en sus intrincadas relaciones con estratos tales como la frontera y la diáspora. Así, centramos la atención en el éxodo como experiencia y en los estratos protofundadores de la comprensión de la migración. Con esta mirada, se dan tres pasos, a saber, se caracteriza la relación existente entre 1. El éxodo y la constitución trascendental; se establece la interrelación entre 2. La frontera y la comunidad de pertenencia; y, finalmente, se mira cómo 3. La diáspora opera la constitución trascendental de la esperanza. A manera de 4. Conclusiones se vuelve la atención a la constitución trascendental como fundamento de la ética.
\end{abstract}

Palabras clave: fenomenología, alteridad, ética, normas trascendentales de la razón, compasión.

\section{The exodus: the founding structure of migration Scope of the transcendental constitution of the passer-by as an ethical foundation}

\begin{abstract}
Migration like exile, alongside the stranger and the stranger, have been the subject of phenomenological research. In this study a small step is taken regarding the phenomenology of migration. In particular, a deepening is carried out around a founding stratum: the exodus in its intricate relationships with strata such as the border and the diaspora. Thus, we focus attention on the exodus as experience and on the foundational layers of the understanding of migration. With this view, three steps are taken, namely, the relationship between the exodus and the transcendental constitution is characterized; the interrelation is established between 2. The border and the community of belonging; and, finally, we look at how 3. The diaspora operates the transcendental constitution of hope. By way of 4 . Conclusions, attention is turned to the transcendental constitution as the foundation of ethics.
\end{abstract}

Key words: phenomenology, alterity, ethics, transcendental norms of reason, compassion.

* Doctor en Educación por la Universidad Pedagógica Nacional (Bogotá, Colombia), donde es además Profesor titular. Coordinador del grupo de investigación interinstitucional Filosofía y Enseñanza de la Filosofía. Entre sus muchas publicaciones destacan los libros: Problemas teóricos y metodológicos de la fenomenología (2012), y Ausencia y Presencia de Dios: 10 estudios fenomenológicos (2011). 
¿Cómo proceder en un análisis fenomenológico del éxodo? Para responder a lo anterior se debe tener en cuenta que: “(a) [la fenomenología] como ciencia falible, [...] epistemológicamente no se diferencia de las demás prácticas de investigación" (Vargas Guillén, 2012: 13); y b) la fenomenología es esencialmente un método, por eso tiene principios y no procedimientos (Vargas Guillén, 2012). Según Husserl debe existir una ciencia filosófica fundamental, esto es, la fenomenología como ciencia rigurosa. Dado que con ésta se logra un conocimiento universal y absolutamente justificado, por ello se debe desarrollar un método filosófico "con el que se abre a la intuición concreta el reino desconocido de la subjetividad trascendental" (Husserl, 2002). Entendida la subjetividad como la fuente de la constitución del sentido, pero para llegar a ésta se debe llevar a cabo el método radical de la fenomenología, a saber, la reducción fenomenológica. Con esta última se alcanza el reino de la subjetividad trascendental fundada en el ego cogito y una actitud fenomenológica. Lo anterior solo es posible si se desconecta

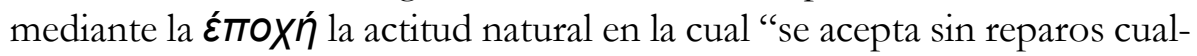
quier tipo de supuestos, prejuicios y valoraciones, apropiándonos de todo lo que se presenta en el ámbito de nuestra experiencia como lo realmente existente y válido" (Aguirre, 2014: 81).

$\mathrm{Al}$ estar en la actitud fenomenológica se empieza a fenomenologizar. Este último entendido como "un quehacer que se rige por el principio de corregibilidad: lo que aparece como horizonte se me da siempre en y desde mi perspectiva" (Vargas Guillén, 2012: 16). Cuando se observa un objeto, por ejemplo, un televisor, se ve solo un escorzo de este - la parte anterior- pero quedan escorzos no vistos - la parte posterior - y, por el principio antes mencionado, lo observado por uno puede ser observado por el otro y viceversa. "La fenomenología tematiza; no sistematiza. Tematizar es 'volver la atención a algo"' (como se cita en Vargas Guillén, 2012: 16). Entonces al fenomenologizar, se capta la experiencia subjetiva con respecto al mundo y luego se 'desplaza la mirada' hacia cómo se da la constitución de las objetividades de ese mundo. Lo anterior no constituye un sistema sin regreso, sino por el contrario cada vez se puede volver a comenzar de nuevo, según sea la 'cosa' que se objetiva.

La fenomenología por tanto va a las cosas mismas para describir "cómo se dan las cosas para el sujeto, en primera persona" (Vargas Guillén, 2012: 19). Para lograr lo anterior se debe hacer una desconexión de la actitud natural mediante la reducción trascendental. Con esta última se logra obtener la actitud reflexiva, entendida como "la puesta en funcionamiento del sujeto como constituyente, como constituidor del sentido". Ahora, cuando el sujeto 
está en esta actitud fenomenológica se descubre la estructura intencional de la conciencia, esto es, "para cualquier pensamiento — noesis - hay como polo correlativo algo pensado — noema—" (Vargas Guillén, 2012: 21). Y estas dos - la noesis y el noema - siempre están en correlación: por más que se enfatice en uno, el otro no desaparece. Teniendo presente lo anterior el sujeto tematiza, es decir, vuelve la atención sobre algo, para captar el todo de lo dado y empezar a describir los procesos de la constitución de sentido. Sin olvidar que lo tematizado puede tener variaciones, dado que una misma cosa puede darse de distintas maneras. Al permitir la variación se hace posible la descripción de esencias, dado que se capta lo invariante en la variación, a saber, la esencia. Captando la esencia, el fenomenólogo pone en acción la dimensión intersubjetiva de la investigación fenomenológica en donde se despliega el Zigzag de/en la tematización dado que es "inherente al fenomenologizar [...] el reconocimiento de que todo darse es parcial [...], corregible, [...]. Se trata sí de una ciencia rigurosa, pero falible (Vargas Guillén, 2012: 26). Lo descrito es condición de posibilidad para proceder en un análisis fenomenológico del éxodo.

\section{EL ÉXODO Y LA CONSTITUCIÓN TRASCENDENTAL}

El éxodo es un proceso. Uno de sus efectos es la migración (Vargas Guillén \& Muñoz, 2019). La experiencia infortunada de algunos de los venezolanos, en su proximidad en nuestras vidas, en el éxodo, es la de perder la vida en el intento. Mientras los migrantes son un rostro, un cuerpo, una presencia; el éxodo crea unas situaciones de invisibilidad, de anonimato, de ausencia. Si la fenomenología y la filosofía de la alteridad, en la dirección levinasiana, ofrece una aproximación a la figura del extranjero, todavía fenomenológicamente se exige -incluso en la vía levinasiana- ir en pos de esa pasividad más pasiva: la de quienes se encuentran en el proceso, en el desplazamiento, en el éxodo.

Se trata, entonces, de entender la situación de pérdida: del rostro propio, del rostro de los otros, de la incertidumbre de los rostros que se topan a la vera del camino; también del anonimato de los viandantes - cuando los hay-, que son primero unos extraños u otros hasta que emerge así sea funcionalmente una 'solidaridad mecánica'; el éxodo es la configuración de la ausencia: no están los rostros, los cuerpos, de siempre y, todavía, no hay otros que estén ahí, en el entorno, como parte del nosotros.

La mayor dificultad para acceder a la experiencia del éxodo es que sólo se puede ver, y comprender, ante o expost, in vivo la tiene en soledad —así sea un grupo más o menos grande el que se desplaza-cada quien, intuito personae. La cosa misma es que en el éxodo cada quien sigue siendo sujeto de derechos, pero su vulnerabilidad es extrema: se carece de instituciones, de 
referentes, de procedimientos para ejercerlos (Waldenfels, 2006; 2007). De hecho, la ciudadanía se esfuma: no se es de aquí ni de allá. En el éxodo priman, entonces, los derechos humanos, en su vaga generalidad, sobre los derechos ciudadanos: se conserva la nacionalidad, pero no se puede ejercer la ciudadanía: la protesta, el voto, el reclamo o exigencia de la salud, de la educación y, sólo muy parcialmente, la justicia. Entonces, prevalecen: el derecho al nombre, pero puede ser fácilmente violado el derecho al buen nombre; a la nacionalidad, pero puede ser, mutatis mutandis, criminalizada; a la libre expresión, pero puede ser calificada de omisión extranjera; y así sucesivamente.

En el éxodo se pierde el estatus de ciudadano; y, en muchos casos, de persona humana, con derechos humanos, plenos y con libre ejercicio. Lo que resulta, entonces, es que la figura de la alteridad se profundiza y llega a un nivel más rotundo en la situación de éxodo, toda vez que ese rostro se reduce a un plano virtual: una presencia-ausente o una ausencia-presente puesto que en el éxodo la persona no está aquí, ni allá. Todavía tiene por referencia la familia, el barrio, la ciudad, el Estado en el cual ha configurado sus comunidades de pertenencia; pero fácticamente éstas se han borrado, y, sin embargo, están presentes en la configuración del sí mismo. Entonces se ha virtualizado toda su red de relaciones y, con ello, sus habitualidades, sus interrelaciones, su sistema de los lugares. También el lugar al que aspira a llegar es una imagen vaga, una representación vacía de contenido, una intención vacía: ha oído que allá hay esto o lo otro, tales o cuales oportunidades o dificultades, supone el paisaje, los rostros, los cuerpos, los alimentos, los usos, las costumbres. Es, pues, una dación virtual del poderllegar-a-ser.

El éxodo es una suerte de situación originaria de desamparo. Quien podría amparar sólo tiene una dación virtual del que está en éxodo: quién viene, de dónde, por qué, a qué, con quién, para qué. Es sólo una presentación dada en imagen de un factum: el que ya ha migrado, lo que se ha vivido - si es el caso- al migrar, etc.; e, incluso, esa dación acontece como fictum: lo que podría ser o llegar a ser, sin correspondiente polo intencional, una cuasidación, una cuasiintuición (Husserl, 1980: Texto No. 18). Entonces no hay amparo ni del lado del que se está desplazando ni de aquel hacia el que se está desplazando, justamente por eso está en la situación de éxodo, del que puede e incluso quiere acoger.

Desde luego, no es que quien esté en la situación de éxodo no esté, ahí, en el mundo; en efecto, lo está; y está en una situación no visible. De modo que la intencionalidad, con él, es una responsabilidad ética de reclamo abstracto de la humanidad de ese otro: que no veo, que no escucho, que no me reclama con su presencia. Antes bien, la eticidad de ese reclamo de la intencionalidad como responsabilidad se erige sobre la virtualidad de ausencia- 
presente y de la presencia-ausente del otro; así es como se puede, ahora, tematizar el éxodo: como un horizonte de la alteridad que reclama sin la gestualidad del rostro, sin la evidencia del cuerpo, en fin, sin su presencia. La paradoja de este reclamo es que viene de lo alto, e, incluso, de lo abstracto de la posibilidad. Parecen existir todos los motivos y las razones para desplegar la solidaridad, pero el reclamo no es una evidencia física, sino una evidencia intelectual que adquiere una carga o una connotación moral. Incluso se puede decir: la solidaridad con el otro, en situación de éxodo, es una evidencia intelectual que se torna, con motivos y razones, evidencia moral.

Lo que cuestiona, en su radicalidad, el éxodo es la sensibilidad moral, el ser de nuestra moralidad. En fin, lo que cuestiona es, justamente, cómo los estados mentales de segundo orden (Nenon, 1996) se pueden tornar sensibilidad moral y, con ello, estados mentales de primer orden. No es la emocionalidad o la afectividad la que despliega el nexo moral con quienes están en la situación del éxodo; en cambio, es la comprensión intelectual del poder 10 estar)-ser o poder-llegar-a-ser (o estar) en situación de éxodo lo que despliega la solidaridad.

Si la fenomenología ha hecho un aporte a la ética, al entender la intencionalidad como responsabilidad (Hoyos Vásquez, 1976), es exactamente porque da a entender que el otro es una dación, más allá de la experiencia fáctica, una dación eidética, esto es, intuitiva; que el otro, en cuanto fenómeno, tiene que ser comprendido más allá del rostro — con sus gestos, sus expresiones, sus proposiciones-. Entonces la solidaridad no es fundada en relación con otro de carne y hueso, sino con cualquiera, in abstracto, que cae en la situación de desamparo.

El Factum de la experiencia de lo extraño (no-yo) se presenta como experiencia de un mundo objetivo y de otros (no-yo en la forma: otro yo) en él. Se muestra un mundo reducido como trascendencia inmanente. El mundo exterior es la trascendencia primordial, que, a pesar de su identidad en cuanto unidad sintética de un sistema infinito de mis potencialidades, todavía es una parte determinante de mi serpropio y concreto como ego (Husserl, 1911: $\$ 48)$.

Lo extraño en sí primero, por tanto, es el otro yo. Está implícito en la esencia de esta constitución, que se eleva a partir de los puros otros (que aún no tienen un sentido mundanal), el hecho de que los otros para mí no permanecen aislados, sino que, por el contrario, se constituye (naturalmente, en la esfera de mi propiedad) una comunidad de yoes, que me incluye a mí mismo como una comunidad de yoes que existen los unos con y para los otros y, en última, instancia una comunidad de mónadas, en cuanto comunidad que (en su intencionalidad constituyente comunizada) constituye el mundo uno e idéntico. En este mundo se presentan nuevamente todos los yoes, pero en una apercepción objetivante con el sentido 
'hombres', es decir, 'hombres psicofísicos' como objetos del mundo (Husserl, 1911: \$49).

Si la sensibilidad moral respecto al otro (Hoyos Vásquez \& Vargas Guillén, 2002) puede ser formada y fundada es porque las razones, en su configuración trascendental, pueden desplegar las emociones, motivos, formas de acción, experiencias de vida. No se trata de zozobrar en una experiencia patética que lleva a la compasión; antes bien, es la razón, sus clarificaciones trascendentales, la que funda la compasión.

La compasión es, a su modo, una manifestación de la empatía. Ésta puede desplegarse fácticamente como simpatía, apatía o antipatía. Este despliegue es tanto ciego como anónimo: no clarifica motivos, no establece razones para su darse. La compasión es un modo radical de empatía si, y sólo si, está fundado en razones que ofrecen motivos para comprometerse con y actuar por el otro; no porque sea mi vecino, o mi amigo, o mi familiar; sino porque es, en sí, humano, reclamo activo o pasivo de toda posibilidad de humanidad.

Si se quiere, el descubrimiento de la empatía como fundamento de la relación con quien está en la situación de éxodo es apertura al reclamo infinito del otro; sólo que ahora es un reclamo en mí y desde mí. Puede verse como una voz interior, un soliloquio, pero es una visión errónea. El reclamo aparece en mí como una constitución trascendental del sentido: es el otro el que clama y reclama, sin rostro, sin voz, sin cuerpo, in absentia. Es la voz. de la razón que se explicita por su propia fuerza; es la voz que hace audible la razón del éxodo, la razón de los vencidos, la razón del débil.

La fenomenología del éxodo es una situación que lleva o conduce al descubrimiento de la razón trascendental como condición de posibilidad de comprensión, abstracta, del otro (Husserl, 2002: 311-340); y, en ese descubrimiento funda la sensibilidad, la motivación, la evidencia moral y la praxis.

El comienzo de la fenomenología es, desde siempre, la intersubjetividad: la reducción del otro a esfera de propiedad, el analogon (Husserl, 1952: \44), la constitución trascendental del otro. En fin, ¿cómo realizar el compromiso ético con el otro, más allá de las etnias, las nacionalidades, los partidos, las ideologías, los intereses personales, sociales, económicos y políticos? Esta es la pregunta que obliga a resituar el fenómeno de la experiencia del éxodo.

Entre tanto, el fin de la fenomenología es, sin más, el descubrimiento ético-cognitivo (Husserl, 2002: 311-340), en el orden personal y en el científico, de la absoluta responsabilidad como intencionalidad; el fin es hallar evidencias que valgan para uno y valgan para todos; el fin, al cabo, es descubrir racionalmente las razones y los motivos para actuar moralmente. El éxodo exige un nivel de abstracción, de explicitación de raz̧ones. Éstas son las que permiten la dación del fenómeno; si se quiere, éste es un fenómeno 
saturado puesto que su aparecer es sólo indirecto. Y, sin embargo, la dación ofrece, por estados mentales de segundo orden, en persona la manifestación eidética del otro (Gamboa Sarmiento, 2010). Por supuesto, esta manifestación no es sólo alusiva o tendiente (in tendere) a la idea del otro; el polo correlativo desplegado o escorzado por razones implica —así sea virtualmente- el rostro, el cuerpo, del otro en situación de éxodo.

La dación virtual del otro, en situación de éxodo, es, entonces, una cuasidación; e, igualmente, su rostro y su cuerpo: son cuasiintuidos (Husserl, 1980: Texto No. 18). Es, pues, la constitución trascendental la que modaliza tanto fantasía como imaginación. La fantasía es dación del phantasma, sin dato hylético; la imaginación es dación que, en últimas reenvía a percepciones actuales o previas. Entonces, no es que la cuasidación, intuitiva, o mejor: cuasiintuitiva, derive del orden de la imaginación o de la fantasía, sino que la constitución trascendental implica que devenga o se instancie como imagen en unos casos o como phantasma en otros.

La sensibilidad moral que se configura en relación con quien está en situación de éxodo es condición necesaria de la emergencia de la solidaridad. Pero esta sensibilidad no emerge y se despliega por una empatía fundada en la interacción rostro a rostro, cuerpo a cuerpo, sino de la intersubjetividad trascendental (Husserl, 1952: \44). Ésta es la que funda la razón; ella exige recurso tanto a la fantasía o como a la imaginación para que ofrezca un cuasiquien - en realidad, nadie o ninguno- que puede ser instanciado como un quien - que puede ser uno, alguno, cualquiera, todos- como referente de todas las posibilidades de dación, como fenómeno. Este fenómeno se manifiesta, primero, en su estructura; posteriormente, en sus múltiples daciones como factum en unos casos y como fictum en otros (Husserl, 1980: Texto No. 18).

Quienes están en situación de éxodo no tienen, desde sí mismos, la posibilidad de comprender la dación del fenómeno que están viviendo. Sólo la pueden comprender en o como efecto del pensamiento. Una dación en la forma de representificación es el principio de la fenomenología del éxodo para quien lo vive. En su presentificación como vivencia, bic et nunc, es mutatis mutandis innombrable: no sólo no llegan las palabras, también el sentido de la vivencia se escapa, se torna inasible. Ya, como migrante, la narración del éxodo vivido es el registro de un recuerdo. Siempre el migrante podrá variar la narración según su posición de existencia, en relación con los intereses que motive su diálogo o su interacción.

Sin embargo, si el que estuvo en situación de éxodo piensa el desplazamiento de quienes lo están viviendo: la comprensión sólo la logra por la constitución trascendental del sentido. La empatía del migrante con quienes están en situación de éxodo deviene como intersubjetividad trascendental. $\mathrm{Al}$ comprender, en representificación, trascendentalmente a nadie o a cualquiera: 
también comprende su propia experiencia, en cuanto vivida; en cuanto la puede vivir, de nuevo, en primera persona; en cuanto la puede vivir cualquiera, en cualquier momento. La solidaridad del que estuvo en situación de éxodo con quien la está viviendo, hic et nunc, es la misma o idéntica de la que tiene con éste quien no ha vivido, jamás, esa experiencia.

Contra Levinas: la empiricidad del rostro, el reclamo del gesto de dolor: es dación inmediata, perceptual. Es, sin más, una superficie. La radicalidad del otro se ofrece trascendentalmente: más allá de todo rostro, de todo cuerpo. Con Husserl: el amor, la solidaridad, en fin, las diversas formas de la empatía y de las formas de pertenencia sólo se conquistan trascendentalmente. Si la solidaridad viene de la empiricidad del ego tenderá a desaparecer con la variación de sus posiciones de existencia; en cambio, cuando la solidaridad - tanto los valores como la sensibilidad moral- están fundados en razón: se ofrecen como una verdad, como parte integrante de la philosophia perennis (Husserl, 1968: 301).

La figura levinasiana del extranjero puede aludir al migrante, no a quien está en situación de éxodo. Una de las consecuencias del éxodo es la migración; también es consecuencia: la relación con la diáspora y con la frontera. No hay éxodo que no implique traspasar frontera. En cambio, puede haber éxodo que conduzca, o no, a la diáspora; en fin, a partir de un lugar de origen sí puede suceder que devenga la dispersión de la comunidad de origen por diversos lugares del mundo; que se reconfigure un conjunto de comunidades de un mismo origen o una misma condición establecida en distintas latitudes.

\section{LA FRONTERA Y LA COMUNIDAD DE PERTENENCIA}

Desde luego, las fronteras, además de una definición geopolítica, siempre son fruto de declaraciones formales, tipo Acuerdo o Tratado, por ejemplo, entre los Estados. No siempre, y raramente coinciden, con las regiones y las culturas que se asientan en ella: la frontera entre Venezuela y Colombia se asienta, en gran medida sobre los Llanos Orientales de ambos países; el Caribe congrega la Costa Atlántica colombiana tanto como la venezolana, la panameña, las islas (San Andrés, Cuba, Haití, República Dominicana, etc.); el asentamiento de los pastos, y de pueblos ancestrales que tuvieron por lingua franca el quechua, se extiende desde el Cauca y $\mathrm{Na}$ riño hasta el Perú; las comunidades vernáculas Wayuu se asientan entre la Guajira colombiana y Venezuela; etc.

Las fronteras culturales, en los casos mencionados, son borrosas. Los miembros de comunidades fronterizas: van y vienen de un lado a otro, mayoritariamente, sin registros migratorios; estructuralmente lo hacen, a menudo, por redes de parentesco. En consecuencia, se definen por formas 
de pertenencia. La movilización dentro de estas fronteras más que un éxodo implica un desplazamiento, temporal, que no conlleva desarraigo del lugar de origen. El caso de la comunidad Wayuu ilustra cómo hay desplazamiento.

Las fronteras estatales, en cambio, son políticas y jurídicas; definen las formalidades migratorias. Se traducen, en variado rango, en derechos y alternativas de ejercicio de los mismos. Implican la legislación interna de cada uno de los Estados; y, a su vez, usan principios de analogía y traducción entre sus legislaciones y las de las ligas de naciones y de Estados. Las diferencias de unos Estados con otros, en relación con sus fronteras, configuran diferendos. Normalmente, la falta de acuerdo entre los Estados se trata con terceros: ligas de naciones y de Estados; entre tanto las resuelven las fronteras en litigio, se toman vigentes las que se establecen en acuerdos o tratados previos, existentes.

La vivencia de la frontera, como experiencia personal o comunitaria, es más o menos porosa. Sí, puede ser que el sujeto traspase una frontera formal, que presente el pasaporte, que lo sellen, etc. Pero la situación de éxodo muestra la 'porosidad' de las fronteras: no son, necesariamente, un lugar formal de migración. El éxodo se caracteriza por la informalidad ante el paso de la frontera. Si hay paso de frontera formal, y, consecuentemente, formalización del traspaso de ella, se tiene el fenómeno de la migración; el éxodo es, en ese sentido, una anomalía de la migración: hay unos claros antes y después. Así, entonces, la frontera y, en especial, el modo de 'traspasarla', es, a su vez, la diferencia entre éxodo y migración, entre ilegalidad y legalidad, entre privación y acceso al derecho.

La frontera constituye las posibilidades de comprensión subjetiva de la pertenencia o del desarraigo, a una familia, a una comunidad, a una nación, a una comunidad de naciones, a un Estado, etc. En rigor, también la pareja, la familia, el barrio: tienen límites, bordes, fronteras. Desde luego, son menos formales que las fronteras políticas de los Estados. También configurar una pareja o una familia implica construir limites, que crean bordes o fronteras; en un comienzo más menos borrosos y dependientes de las primeras adscripciones o pertenencias. Progresivamente la configuración cobra legaliformidad: hace visible la validez de lo que cabe y lo que se excluye del entorno.

La vivencia primaria de la frontera, en primera persona (Herrera Restrepo, 2002), se tiene en la familia; y, subsidiariamente, en el barrio, en la escuela, en la iglesia, etc. Por analogía con esta vivencia comprendemos las fronteras de la ciudad, del país, de la nación. Sólo se puede experimentar el éxodo por la relación configurada por el límite, con el borde, en relación con la frontera. También se tienen fronteras entre las profesiones, las ideologías, los partidos, los credos, los fines a los que se tiende. En su 
ser personal cada quien se pone límites; desde ellos puede, o no, recibir al otro, acogerlo, e, igualmente, rechazarlo, experimentar la agresión; desde luego, el límite que traza la personalidad, analógicamente, se puede llamar frontera ${ }^{1}$.

La relación con el límite en el orden personal configura tanto la adscripción o pertenencia a comunidades - a parejas, familias, naciones, etc., personalidades de orden superior - como el desarraigo con respecto a ellas. El límite crea, a su vez, la diferencia entre el nosotros y los otros. Los límites son fronteras entre las comunidades; se puede entrar en ellas y tener reconocimiento en su interior; también en ellas puede haber repulsa, o, indiferencia. La frontera es vivida como límite entre el extraño y el prójimo. Aquél no sabe las reglas de la comunidad, sus símbolos, sus ritos, sus mitos (Schutz, 2012: 27-56); éste ha convertido ese acervo en habitualidades, en formas de vida, en experiencia.

Con todo, ¿cómo se re-conoce al otro como "otro real"? Para Husserl está en cuestión: a) la constitución trascendental, b) el sentido trascendental de los sujetos extraños y c) un estrato universal de sentido que, irradiando desde ellos, hace en general posible para mí un mundo objetivo. Por tal motivo los "sujetos extraños" no son todavía en cuanto sujetos objetivos, en cuanto existentes en el mundo. Debemos realizar por tanto una epojé temática dentro de la esfera trascendental universal. Con ello llevamos a cabo una reducción a mi esfera trascendental propia. Se tiene dos egos, uno el ego propio y el otro por la preeminente intencionalidad que se constituye el nuevo sentido de ser que va más allá de mi ego monádico en su propiedad misma; se constituye un ego, no como yo-mismo; sino como reflejándose en mi yo propio, en mi mónada. Pero el segundo ego no está ahí simplemente, ni es estrictamente dado en sí mismo; sino que es constituido como alter ego. El ego que designa la expresión alter ego como uno de sus momentos: soy yo mismo en mi propiedad. El otro, según su sentido constituido remite a mí mismo. Es un analogon de mí mismo y, sin embargo, no es un analogon en sentido habitual (Husserl, 1911: \$44).

Cada mónada es realmente una unidad absolutamente cerrada; pero, de todos modos, la penetración intencional irreal de los otros en mi primordialidad no es irreal en el sentido de un ser allí dentro de sueños o de un ser representado según la manera de una mera fantasía. Un existente está en comunidad intencional con un existente. Se trata de una conexión esencialmente peculiar, de una comunidad efectiva, de aquélla que hace trascendentalmente posible el ser de un mundo, de un mundo de hombres y de cosas (Husserl, 1911: \56).

1 En el uso corriente, nos referimos más al límite que a la frontera, en relación con la persona. Aquí interesa la validez analógica de la relación entre estos dos títulos. 
Ahora bien, por "constitución psíquica del mundo objetivo" se comprende, por ejemplo, mi experiencia real y posible del mundo, la mía, es decir, la del yo que se experimenta a sí mismo como hombre. Esta experiencia es más o menos completa; pero es en cuanto tiene siempre un horizonte abierto e indeterminado. Para todo hombre, cada uno de los otros se encuentra en este horizonte - físicamente, psicofísicamente, intrapsíquicamente- en cuanto reino abierto e infinito al que se puede acceder, bien o mal, aunque de modo deficiente en la mayoría de los casos (Husserl, 1911: §56).

De cualquier modo, yo no apercibo al otro, simplemente, como duplicado de mí mismo, es decir, con mi esfera original o con una igual, ni con los modos espaciales de aparición que me son propios a partir de mi "aquî", sino que, examinando la cuestión más detenidamente, yo lo apercibo con modos espaciales de aparición iguales a los que yo tendría si yo fuera hasta allí y estuviera allí. También el otro es apercibido apresentativamente como el yo de un mundo primordial. En esta apresentación, por tanto, el cuerpo físico que se presenta en mi esfera monádica, en el modo allí y que es apercibido como cuerpo físicoorgánico extraño, como cuerpo orgánico del alter ego, indica el mismo cuerpo físico en el modo del aquí, en cuanto experimentado por el otro en su esfera monádica (Husserl, 1911: $\$ 53)$.

$\mathrm{Al}$ efectuar esa abstracción, nos queda un estrato unitario y coherente del fenómeno "mundo", del correlato trascendental de la experiencia del mundo que se despliega de una manera continua y concordante. Así pertenece a mi propiedad, purificada de todo sentido de una subjetividad extraña, sentido de mera naturaleza que también ha perdido precisamente ese para cada uno y que, por tanto, de ningún modo debe ser tomado por un estrato abstractivo del mundo mismo o bien de su sentido, de mi propiedad y los sistemas de lo que me es extraño. Yo, el yo humano (el yo psicofísico) reducido, soy, pues, constituido como miembro del mundo, con un múltiple fuera de mí, pero yo mismo constituyo todo esto en mi psique y lo llevo intencionalmente en mí en tanto fronteras (Husserl, 1911: \$44).

Vamos, ahora, al asunto puesto en cuestión: las fronteras se pueden traspasar de múltiples maneras y con múltiples propósitos. Si las traspasan las fuerzas armadas, o los grupos ilegales armados de una nación, se trata o se puede tratar como una invasión. Normalmente no se hace como una acción civil, con revisión de pasaportes, y las demás formalidades. A su turno, si la frontera la cruza un grupo de estudiantes, normalmente se surten todas las formalidades; se opera como un intercambio cultural; en fin, se lleva cabo una relación que hermana y expande el sentido de pertenen- 
cia. En cambio, si ocurre el cruce de la frontera por desplazamiento forzado, el traspaso de la frontera toma las formas del éxodo, en los casos en que es ilegal; o, de la migración, cuando es legal. Por supuesto, puede haber más variantes del traspaso de las fronteras: la comercial, la turística, la política - embajadores, agregados culturales, etc.-.

De nuevo, aquí interesa el éxodo. Ahora se ve con más precisión: la persona en situación de éxodo es un paria. Ha perdido todo nexo, y en su desplazamiento, no sabe dónde está y tampoco a dónde va a llegar. Su situación de ilegalidad la mantiene en un estado de desconexión con respecto a todo vínculo formal de pertenencia. Desde luego, no puede vivir sin los otros. Ahora son sus compañeros viandantes. Aparece una forma de solidaridad: la solidaridad mecánica. Su vínculo con sus compañeros de infortunio dura mientras se extienda la marcha. Una vez concluida ésta, cada quien está al descampado y tenderá a buscar, en primer lugar, la resolución de su propio estatus; a insertarse a algunas redes de relaciones, a crear un tejido. Es, más bien, accidental que el vínculo con los demás viandantes del éxodo vaya más allá.

La situación de éxodo se extiende para la persona que la vive hasta tanto no legaliza su estatus. Quien permanece en ilegalidad, una y otra vez, está a punto de tenerse que volver a mover. Es más vulnerable. Su vínculo y su red de relaciones son frágiles porque puede ser denunciado, retenido, expulsado. En estos casos, el éxodo no sólo se vincula a la frontera. Éste se extiende tanto cuanto no pertenece, no está incluido, no puede reclamar. De este modo, es, virtualmente, un rostro y un cuerpo que se fugan, huyen, se diluyen. Su situación es la del anonimato. Su poder-estar está asociado a su invisibilidad. El que continúa en éxodo tiene relación a un país, o a una nación, que no es el o la suya propios. En relación con el país: ve el paisaje, en lo posible se acomoda a él, a sus gentes. En relación con la nación: enfrenta tradiciones, costumbres, modos de vida, etc., que le son ajenos; en consecuencia, es un extraño para los nacionales; y, él mismo vive la enajenación y el extrañamiento en relación consigo mismo, con sus hábitos, sus costumbres, sus ritos, sus mitos, su lengua, sus mismos o prójimos. A quien se le extiende la situación de éxodo en su nuevo lugar, en rigor, no tiene residencia; no es, ni formal ni materialmente, sujeto de la acogida; en fin, es otro, el otro (Vargas Guillén \& Muñoz, 2019: 37-39).

Si la frontera, los bordes o los límites son una experiencia sui en que se vive la radicalidad del extrañamiento en el éxodo es, justamente, porque no hay asidero, pertenencia, vínculo. Cuando una mujer o un hombre - en fin, la persona - en la situación de éxodo son vejados, de un todo, se ha desplegado la imposibilidad de trazar un límite. De igual modo, se borra 
el límite, y la posibilidad de ejercerlo, cuando la persona es esclavizada, explotada. En resultas, lo que se pierde o difumina o disuelve en el éxodo es la persona, la personalidad.

Perdidas, por la situación de éxodo, la persona y la personalidad, igualmente, se pierden los vínculos y la pertenencia; se opera, entonces, un desgonzamiento o desanclaje de las personalidades de orden superior - la familia, el barrio, la iglesia, la escuela, la ciudad, la nación, el Estado, etc.- (Husserl, 1973: 218). Es la situación del paria. Poder volver a ver en cada quien - alguien, alguno- en situación de éxodo como persona y contribuir al proceso de inclusión o recuperación o reinstauración de ella en personalidades de orden superior exige, de nuevo, su constitución trascendental mediante los estados mentales de segundo orden como fundación de la ética. En fin, ésta deriva de una exigencia de la razón. Sólo desde allí se pasa de la imputación de cargas - racistas, sexistas, xenófobas, etc.- que operan anónimamente como prejuicios. Si esta clarificación trascendental es llevada a cabo, entonces se abre la comprensión - incluso de las acciones o los actos criminales- de quien está en situación de éxodo, justamente, porque al perder todo nexo y tejido social, en total desamparo, recurre o puede recurrir a las conductas más primarias que, incluso, pueden revestir modos antisociales.

La comprensión del éxodo, de la persona en esta situación, desde la constitución trascendental no justifica las acciones criminales, pero abre la posibilidad de establecer la co-responsabilidad de todos y cada uno de los ciudadanos con la pérdida de límites a la que ha sido impulsada o coactivamente conducida. Aquí aparece un reclamo trascendental del otro. Este reclamo no es dicho por quien padece el éxodo. Tiene que ser expresado como exigencia de la razón, como fundamento y fundación de la comprensión y de la acción ética, respectivamente. Sólo a partir de allí es posible, se traspase como sea y por donde sea la frontera, acceder al otro y comprometerse, desde la compasión fundada en razón.

\section{LA DIÁSPORA OPERA LA CONSTITUCIÓN TRASCENDENTAL DE LA ESPE-} RANZA

Desde luego, los que parten a la incertidumbre del éxodo no sólo toman un camino desconocido. La más de las veces son familias, grupos y comunidades arrojadas al éxodo (Vargas Guillén \& Muñoz, 2019: 45-46). Parten con la esperanza del reencuentro, con promesas e incluso con compromisos de reencuentro. El desplazamiento lo transforma todo: la temporalidad compartida hasta entonces queda congelada; las nuevas vivencias constituyen horizontes desde perspectivas que ya no son comunes. Cada quien cambia tanto Körper como Leib. La unidad al comienzo del éxodo es una configuración imaginaria. Progresivamente se va transformando en ficción. 
Las descripciones del pasado comunitario vivido se van transformado en narraciones que llenan de sentido - presunto, ficcionado, fantasmagóricola comunidad posible.

El habla del suelo común del que se parte al éxodo no sólo se altera en la relación con otros dialectos; algunas de las voces conocidas no designan lo que antes era habitual y familiar; nuevas voces nombran antiguos objetos habituales. La dieta, la gastronomía, la cocina se ven alteradas por los frutos que ofrece el paisaje. También con sus tradiciones y costumbres, quien vive la situación de éxodo altera las del lugar donde llega. Pero es 'extraño': lo que comen, la manera como lo hacen, las ocasiones para prepararlo (Schutz, 2012).

La unidad de base, que obraba la comunidad, si no se disuelve de un todo al menos queda alterada. ¿A qué volver? Quien ha vivido la radicalidad del éxodo: ilegalidad, vejámenes, explotación, esclavitud, etc., se sabe otro de sí mismo, de los que le fueron próximos-prójimos. Tal vez no se atreva a dar a conocer sus peripecias, su historia. Tal vez no quiere que se sepa, que alguien de los que fueron miembros de sus núcleos de pertenencia sepa, por las que pasó; no quiere que esa despersonalización sufrida macule o mancille su ser, la idea que los otros tienen de él. No es cosa de vanidad o de orgullo. Es la marca de lo que no debería pasarle a nadie (Vargas Guillén \& Muñoz, 2019).

Si, si alguien trata de volver: ¿a qué?, ¿para qué? Tal vez el otro, los otros, también cargan su mácula, su mancilla. Quien quiere regresar tiene desconfianza de sí, ha perdido en muchos casos su dignidad. También sospecha o supone que el otro algo le oculta, le ocultará. Las relaciones antaño de confianza y abandono a la piedad del otro se transforman en sospechas despiadadas. Se culpa de lo que ha vivido; culpa a los otros, igualmente. No hay nada del suelo común, aunque las 'cosas' hayan, mutatis mutandis, permanecido en su lugar: la casa ahora no es lar, la cuadra y el barrio no son comunidad, la ciudad no es más familiar o habitual, etc.

¿Qué queda, entonces, tras el éxodo? Un horizonte de posibilidades, más o menos, de reconstrucción. La cura viene de la capacidad de perdón, de olvido, de resguardo de la intimidad, de acogida, de reconocimiento. Desde luego, la diáspora es una partida heteróclita; pero ella misma es un sostén de la perspectiva de llegar-a-ser de nuevo con-los-mismos — que se han tornado otros, extraños- y volver a un tiempo, nuevo, juntos. La diáspora, a pesar de todo y de todos, es un lugar de la esperanza. Acaso es, la diáspora como estructura del éxodo e incluso de la migración, el sostén que sirve y abre el horizonte, la posibilidad, el sentido.

La diáspora reconoce y rememora, una y otra vez, el suelo natal y el lugar de partida; cuando el éxodo se concibe como un paso, como algo que al fin y al cabo terminará, entonces todavía preserva la esperanza, exhorta 
al porvenir. Se vuelve un hontanar, pobre si se quiere, que funda tanto la moralidad como la eticidad. Ahí, de nuevo, se exige la constitución trascendental del sentido del darse de la diáspora: sí, quienes están en la situación de éxodo, han partido; la unidad se ha roto; el extrañamiento o el enajenamiento son un aquí y abora con toda la gravedad del desarraigo. Todo eso y más está en juego. Y, no obstante, la diáspora se extiende como un tenue hilo de pertenencia a una comunidad sida u obrada tanto como a una comunidad posible o por obrar (Nancy, 2001).

Sostener o disolver la esperanza en la diáspora es cosa misma de la ética, fundada trascendentalmente: la facticidad de las vivencias de quien se encuentra en situación de éxodo lleva a la desesperanza que motiva el desamparo; en cambio, la razón trascendental muestra como íntima responsabilidad la exigencia de rememorar el vínculo, de reavivar el sentido posible del reencuentro, la reconfiguración - a pesar de los pesares- de la comunidad posible por obrar. En último término, la reflexión trascendental funda el sentido teleológico, radical de la esperanza.

Entonces, no es que la memorabilidad de la comunidad obrada como la posibilidad de la comunidad por obrar sean una responsabilidad individual de quien se encuentra en la situación del éxodo; antes bien, hacerse cargo de éstas es una de las expresiones fundamentales de la acogida. A quien está en situación de éxodo no sólo se lo acoge como ego solitario; por el contrario, éste porta a los otros en él. Aquí y allá ellos, con todas las variaciones que esto conlleva - puesto que se trata de $s u$ historia; no de un dogma-, la fuente de la moralidad y de la eticidad de quien padece el éxodo es la esperanza que, todavía, gravita en la diáspora. Quien está en la situación de éxodo no sólo ha perdido la comunidad, también la posibilidad de hablar sobre ella, de rememorarla. La acogida da espacio - cobijo y albergue- a las evocaciones, a las narraciones, a la reconfiguración de la comunidad obrada como obrable, hic et nunc, por parte del viandante.

La reflexión trascendental sobre la diáspora halla la esperanza como núcleo fundante de la perspectiva y el horizonte del que está en situación de éxodo, del viandante. Y, no obstante, no se trata de una sacralización o una reificación de la comunidad obrada y obrable; antes bien, la constitución trascendental del sentido de ella apunta a comprender sus límites y sus posibilidades, la mortificación y el gozo que se despliega en ella, las contradicciones y las superaciones que son su suelo natal. Así, entonces, la esperanza que sostiene en la diáspora a los viandantes se configura racionalmente como un horizonte de vida, de encuentro entre personas de carne $y$ bueso que generan vínculos frágiles en personalidades de orden superior igualmente históricas y falibles. La esperanza que sostiene a los viandantes en el éxodo se funda en la evidencia de una humanidad frágil y falible, que establece nexos entre personas, que en su historicidad despliegan vínculos 
e instituciones. Esta reflexión trascendental es la que puede perder, con la pérdida completa de su voz, la persona en la situación de éxodo; es la restitución de esa voz y de la posibilidad de mantener y dar sentido lo que abre la constitución de la intersubjetividad trascendental.

\section{CONCLUSIONES}

Según las indicaciones de Husserl —en las Conferencias de Londres- el análisis fenomenológico implica una investigación ética en donde ésta queda comprendida como prototipo regulativo de una forma peculiar de vida humana. El ser humano debe dejar de vivir día a día y empezar a despertar éticamente, para ser verdaderamente un ser humano ético. Empezar a tener un nuevo modo de vida, una vida de conciencia absolutamente clara, legitimada absolutamente en sí y por sí misma. Si la vida se entrega en general al conocimiento debe tener una legitimación ética, por lo que en última instancia exige leyes que es preciso defender, dado que debe ser una vida centrada en la idea del conocimiento auténtico y verdadero (Husserl, 2002).

Ahora bien, con base en la descripción precedente se sigue, y se concluye en este estudio, que la constitución trascendental es un fundamento de la ética. Ésta, a su vez, hunde sus raíces en la intersubjetividad trascendental. Si bien es cierto que la detrascendentalización de la ética va en procura de la vivencia del ciudadano de a pié, que en esta vía la sensibilidad moral es la condición de posibilidad de las normas trascendentales de la razón (Vargas Guillén, 2018; Vargas, Sesarego \& Guerrero, 2019); la vía que se ha explorado en este estudio es la de la reflexión como base de la eticidad y de la moralidad. Más aún, queda como resultado principal que la fundación detrascendentalizada de la ética es sólo un momento que tiene que ser 'elevado' a eidos, a razones y motivos que valen para uno y valen para todos; en fin, queda como resultado que la detrascendentalización de la ética tiene tanto sentido como valor en cuanto logra ser integrada a la reflexión trascendental. La ética que apela y se basa en las emociones y en la sensibilidad moral está siempre en las márgenes tanto del subjetivismo como del relativismo; por ello se traduce o se puede traducir en contextualismo y, al cabo, en escepticismo.

La constitución trascendental de la ética, en todos los casos, parte de y regresa al mundo de la vida: el éxodo, la situación de éxodo, el viandante, la concreción del desplazamiento forzado de los venezolanos, etc., son datos que se pueden constatar. Sin embargo, su dación implica el orden del concepto, del eidos. Es a partir de éste que el caso se convierte en fenómeno en múltiples manifestaciones, u omnilateralidad, en su dación; ahí es cuando entra en juego el despliegue, primero, de la comprensión como 
primera instancia; y, posteriormente, la ética fundada en razón: la que vale para uno y vale para todos.

La ética no es, entonces, un modelo que depende de los hechos. Antes bien, la comprensión de éstos se ordena según normas trascendentales de la razón. Éstas exhiben la dación y el sentido abstracto de humanidad que en sí y por sí exige la condición de cada persona en particular. Más allá de todo patetismo, la solidaridad se funda en razones y la relación con el alter es comprendida y realizada como un sentido y un valor universales.

Si el éxodo, la frontera y la diáspora son dimensiones de la experiencia humana, si en ellas está en juego tanto la comprensión como la actuación ética es, justamente, porque cualquiera pudiera estar en esas circunstancias. La vuelta a las estructuras eidéticas, desplegadas en los estados mentales de segundo orden, no es cuestión que colma el tiempo del diletante; antes bien, es una tarea que exige la razón misma, de un lado; y, que se despliega como efecto de una exigencia ética.

Si la solidaridad con quien está en situación de éxodo sólo parte del reclamo del rostro, del cuerpo, del viandante, siempre se corre el riesgo de que en su ausencia, de nuevo, sobrevenga la apatía, la indolencia, la indiferencia. En cambio, si las razones son las que llevan a la solidaridad, ésta se mantiene en su universalidad como una demanda.

Es cierto que los rostros, los cuerpos, dolientes: conmueven. Pero más allá de esa conmoción es imperativo volver la mirada la constitución del sentido abstracto de los valores que fundan la comprensión y la acción como horizonte de humanización, como proyecto, como aspiraciones de uno y de cualquiera; con validez intrínseca. Incluso las aspiraciones de las religiones, tómese por caso: “'No matarás?', antes de cualquier toma de posición de fe se puede y se tiene que fundar en razón. Los valores, en su universalidad y su verdad no son asuntos de creencias, de fe, de ideologías. Son una conquista, siempre parcial y perfectible, de la razón como un proyecto de íntima y, paradójicamente, de común realización.

\section{REFERENCIAS}

Aguirre, M. (2014). La epojé como ruptura de la actitud natural: Husserl y Sartre. Versiones, (5), 78-87.

Gamboa Sarmiento, S. C. (2010). Conciencia, estado de conciencia; mente, estado mental. Anuario Colombiano de Fenomenología, 4, 333-354.

Herrera Restrepo, D. (2002). La persona y el mundo de su experiencia. Bogotá: Universidad de San Buenaventura.

Hoyos Vásquez, G. (1976). Intentionalität als Verantwortung. Geschichtsteleologie und Teleologie der Intentionalität bei Husserl. Den Haag: Martinus Nijhoff. 
Hoyos Vásquez, G. \& Vargas Guillén, G. (2002). La teoría de la acción comunicativa como nuevo paradigma de investigación en ciencias sociales: las ciencias de la discusión. Bogotá: Icfes-Ascun.

Husserl, E. (1911). Cartesianische Meditationen una Pariser Vortràge. Dordrecht, Netherlands: Kluwer.

Husserl, E. (1952). Ideen ₹u einer reinen Phänomenologie und phänomenologischen Philosophie. Zweites Buch: Phänomenologische Untersuchungen zur Konstitution. (Hrsg. von M. Biemel). Den Haag: Martinus Nijhoff.

Husserl, E. (1968). Phänomenologische Psychologie. Vorlesungen Sommersemester 1925. (Hrsg. von W. Biemel). Den Haag: Martinus Nijhoff.

Husserl, E. (1973). Zur Phänomenologie der Intersubjektivität. Texte aus dem Nachlass. Dritter Teil: 1929-1935. (Hrsg. von Iso Kern). Den Haag: Martinus Nijhoff.

Husserl, E. (1980). Phantasie, Bildbewusstsein, Erinnerung. Zur Phänomenologie der anschaulichen Vergegenwärtigungen. Texte aus dem Nachlass (1898-1925). (Hrsg. von E. Marbach). Dordrecht: Kluwer.

Husserl, E. (2002). Einleitung in die Philosophie. Vorlesungen 1922/23. (Hrsg. von B. Goossens). Dordrecht: Kluwer.

Nancy, J.-L. (2001). La comunidad desobrada. Madrid: Arena Libros.

Nenon, T. (1996). Husserl's Theory of the Mental. En Nenon, Th. \& Embree, L. (Eds.), Issues in Husserl's Ideas II (pp. 223-235). Dordrecht/Boston/London: Kluwer Academic Publishers.

Schutz, A. (2012). El forastero. Ensayo de psicología social; La vuelta a hogar. En G. Simmel, El extranjero. Sociología del extraño (pp. 27-56). Madrid: Ediciones Sequitur.

Vargas Guillén, G. (2012). Fenomenología, formación y mundo de la vida. Madrid: Editorial Académica Española.

Vargas Guillén, G. (2018). El análisis reflexivo y el método fenomenológico. Contribución a la detrascendentalización de la fenomenología. Investigaciones fenomenológicas, 7, 237-255.

Vargas Guillén, G. \& Muñoz, E. (Eds.) (2019). Aproximación a una fenomenología de la migración. Bogotá: Aula de Humanidades.

Vargas, G., Sesarego, E. \& Guerrero, M. (2019). Formación ética y normas trascendentales de la razón. El problema de la educación ciudadana. Revista Colombiana de Educación, (76), 285-304.

Waldenfels, B. (2006). Grundmotive einer Phänomenologie des Fremden. Frankfurt am Main: Suhrkamp.

Waldenfels, B. (2007). Das Fremde denken. Zeithistorische Forschungen/Studies in Contemporary History, Online-Ausgabe, 4. Disponible en https://zeithistorische-forschungen.de/3-2007/4743 